\title{
Newsletter UICISA-E, dezembro de 2012
}

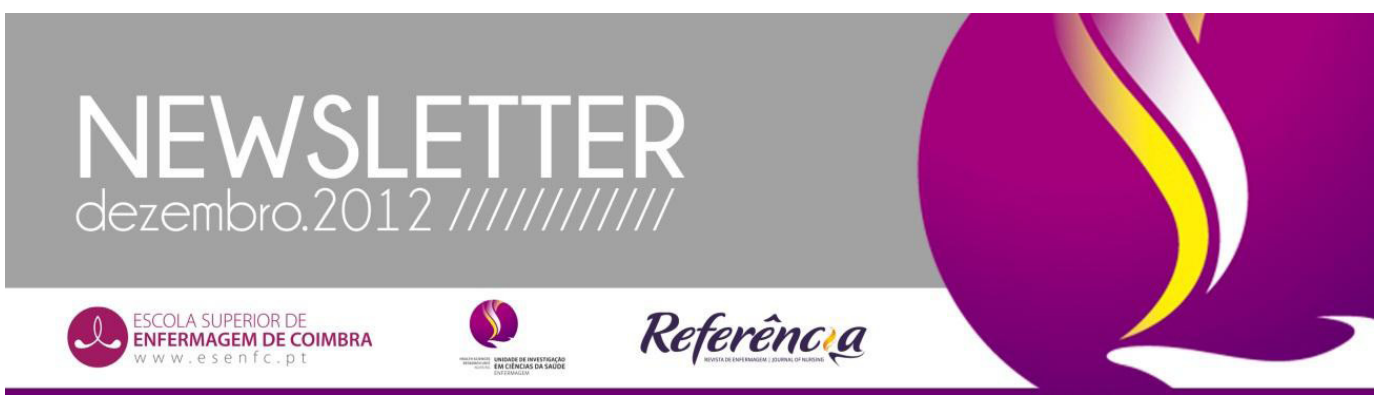

\section{Dezembro 2012}

\section{Comunicaçáo da Ciência}

A "Comunicação da Ciência", enquanto expressão, está associada à produção e divulgação de conhecimento científico, podendo ser alargada para as aplicações atribuídas a esse conhecimento gerado e à comunicação entre investigadores (Carvalho e Cabecinha, 2004). A problemática da Comunicação da Ciência não é novidade visto que Garvey e Griffith apud Valério e Pinheiro (2008) referiram que "a comunicação é um processo que se inicia com a pesquisa e termina com as descobertas incorporadas ao conhecimento científico, sendo a informação parte inseparável da pesquisa.

A interação social é importante no processo de geração e divulgação do conhecimento e, segundo Gross apud Carvalho e Cabecinhas (2004, p.3), os processos de interação social estão envolvidos "na construção do conhecimento científico, na sua "validação" pela comunidade científica e na sua afirmação social".

O Portugal Centre for Evidence Based Practice: an Affiliate Centre of the Joanna Briggs Institute, sediado na Unidade de Investigação em Ciências da Saúde: Enfermagem (UICISA:E) é, atualmente, o único centro português a colaborar com o Joanna Briggs Institute (JBI). O JBI engloba 4 unidades operacionais, sendo uma delas dedicada à Comunicação da Ciência ("Communication Science"). Esta unidade é responsável por organizar eventos locais e internacionais, desenvolver estratégias de comunicação internas e externas e editar publicações.

De forma a divulgar a produção científica, os investigadores da UICISA:E publicam artigos na
Revista de Enfermagem Referência (indexada em bases de dados internacionais) e em outras revistas nacionais. No entanto, os conteúdos científicos publicados em revistas científicas internacionais, indexadas e com fator de impacto têm aumentado. Esta evolução acontece pois as revistas indexadas e com fator de impacto constituem as publicações de maior relevância como indicadores de produtividade científica da Unidade.

No entanto, a comunicação do material científico não se esgota na publicação de artigos científicos. Outras formas de divulgação científica são a participação em encontros científicos, colóquios e conferências (Workshops, posters, comunicações livres, entre outros); em comissões científicas e técnicas; a realização de sessões de educação; a realização de documentários; e a divulgação nos meios de comunicação social.

Neste ano de 2012, com o objetivo de divulgar a produção científica em Enfermagem, a UICISA:E desenvolveu e colaborou no desenvolvimento de diversos eventos científicos.

O III Congresso de Investigação em Enfermagem Ibero-Americano e de Países de Língua Oficial Portuguesa decorreu de 12 a 15 de junho. A sua organização é da responsabilidade da UICISA:E e é de realização bienal. Neste ano, foram realizadas 258 comunicações orais e apresentados 104 posters. Inscreveram-se para o Congresso 321 pessoas inscritas (das quais 193 eram estudantes). Nos workshops participaram 72 pessoas e nas reuniões estiveram presentes 92 pessoas.

A Unidade de Investigação promoveu ainda Seminários de Doutorandos UICISA:E, as Sessões de Educação para a Saúde em Escolas no âmbito do 
projeto "Felizmente" e, periodicamente, as reuniões da Comissão de Ética.

\section{Colaboração da UICISA:E em Eventos Científicos:}

- Jornadas de "Feridas: uma problemática no contexto atual" (15-17 de fevereiro);

- I Encontro Internacional de Enfermagem de Saúde Mental (1-2 de março);

- Congresso de Enfermagem de Reabilitação (23 a 24 de março);

- III Jornadas de Enfermagem Médico-Cirúrgica "A Pessoa em Situação Crítica: complexidade e intervenção" (26-28 de abril);

- IV PEER: Escola de Verão em Educação pelos Pares associada ao III $^{\circ}$ Encontro Anual do ICPHR Colaboração Internacional de Investigação-Acção Participativa em Saúde (07-12 de maio);

- "Controvérsias em Amamentação" (1 de outubro); - Apresentação Oficial do sítio da Internet "Felizmente" (9 de outubro);

- Workshop de "Investigação Participativa em Saúde" (15-17 de outubro);

- III Colóquio de Envelhecimento, Saúde e Cidadania (21 de outubro);

- Jornadas "Expressão e avaliação da Dor" (5 de novembro);
- Workshop "Gestão de Projetos de Investigação Científica" (30 de novembro);

- Semana Internacional da Prevenção do Abuso de Álcool (3-7 de dezembro).

Organizado por Andreia Sofia Marques Pereira (Licenciada em Enfermagem, Bolseira de Investigação na UICISA-E).

\section{Referências Bibliográficas:}

CARVALHO, Anabela; CABECINHAS, Rosa (2004) - Comunicação da Ciência: perspectivas e desafios. Comunicação e Sociedade [em linha]. no 6, p. 5-10. [Consult. 21 Nov. 2012]. Disponível em WWW:URL:<http://repositorium.sdum.u minho.pt/bitstream/1822/2813/1/acarvalho_rcabecinhas_ artComSoc_2004.pdf>

VALÉRIO, Palmira Moriconi; PINHEIRO, Lena Vania Ribeiro (2008) - Da comunicação científica à divulgação. TransInformação [em linha]. Vol. 20, nº 2, p.159-169. [Consult. 26 Nov. 2012]. Disponível em WWW:URL:<http://ridi.ibict. br/handle/123456789/28> . 